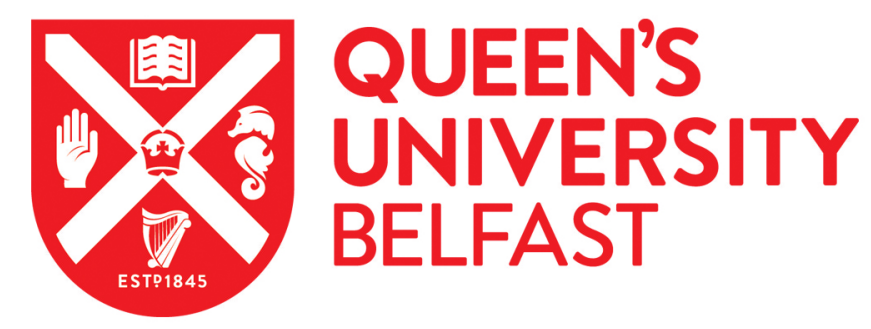

\title{
A novel transdermal protein delivery strategy via electrohydrodynamic coating of PLGA microparticles onto microneedles
}

Angkawinitwong, U., Courtenay, A. J., Rodgers, A., Larraneta, E., McCarthy, H. O., Brocchini, S., Donnelly, R. F., \& Williams, G. R. (2020). A novel transdermal protein delivery strategy via electrohydrodynamic coating of PLGA microparticles onto microneedles. ACS Applied Materials and Interfaces.

https://doi.org/10.1021/acsami.9b22425

Published in:

ACS Applied Materials and Interfaces

Document Version:

Peer reviewed version

Queen's University Belfast - Research Portal:

Link to publication record in Queen's University Belfast Research Portal

Publisher rights

(c) 2020 American Chemical Society. This work is made available online in accordance with the publisher's policies. Please refer to any applicable terms of use of the publisher.

\section{General rights}

Copyright for the publications made accessible via the Queen's University Belfast Research Portal is retained by the author(s) and / or other copyright owners and it is a condition of accessing these publications that users recognise and abide by the legal requirements associated with these rights.

Take down policy

The Research Portal is Queen's institutional repository that provides access to Queen's research output. Every effort has been made to ensure that content in the Research Portal does not infringe any person's rights, or applicable UK laws. If you discover content in the Research Portal that you believe breaches copyright or violates any law, please contact openaccess@qub.ac.uk. 


\section{ACS APPLIED MATERIALS \&INTERFACES}

\section{Biological and Medical Applications of Materials and Interfaces}

\section{A novel transdermal protein delivery strategy via electrohydrodynamic coating of PLGA microparticles onto microneedles}

Ukrit Angkawinitwong, Aaron J. Courtenay, Aoife Rodgers, Eneko Larraneta, Helen O. McCarthy, Steve Brocchini, Ryan F. Donnelly, and Gareth R. Williams

ACS Appl. Mater. Interfaces, Just Accepted Manuscript • DOI: 10.1021/acsami.9b22425 • Publication Date (Web): 18 Feb 2020

Downloaded from pubs.acs.org on February 26, 2020

\section{Just Accepted}

"Just Accepted" manuscripts have been peer-reviewed and accepted for publication. They are posted online prior to technical editing, formatting for publication and author proofing. The American Chemical Society provides "Just Accepted" as a service to the research community to expedite the dissemination of scientific material as soon as possible after acceptance. "Just Accepted" manuscripts appear in full in PDF format accompanied by an HTML abstract. "Just Accepted" manuscripts have been fully peer reviewed, but should not be considered the official version of record. They are citable by the Digital Object Identifier (DOI@). "Just Accepted" is an optional service offered to authors. Therefore, the "Just Accepted" Web site may not include all articles that will be published in the journal. After a manuscript is technically edited and formatted, it will be removed from the "Just Accepted" Web site and published as an ASAP article. Note that technical editing may introduce minor changes to the manuscript text and/or graphics which could affect content, and all legal disclaimers and ethical guidelines that apply to the journal pertain. ACS cannot be held responsible for errors or consequences arising from the use of information contained in these "Just Accepted" manuscripts. 


\title{
A novel transdermal protein delivery strategy via electrohydrodynamic coating of PLGA
}

\section{microparticles onto microneedles}

\author{
Ukrit Angkawinitwong ${ }^{1}$, Aaron J. Courtenay ${ }^{2,3}$, Aoife M. Rodgers ${ }^{2,4}$, Eneko \\ Larrañeta $^{2}$, Helen O. McCarthy ${ }^{2}$, Steve Brocchini ${ }^{1}$, Ryan F. Donnelly ${ }^{2}$, and Gareth \\ R. Williams $^{1 *}$
}

${ }^{1}$ UCL School of Pharmacy, University College London, 29-39 Brunswick Square, London, WC1N 1AX, United Kingdom.

${ }^{2}$ School of Pharmacy, McClay Research Centre, Medical Biology Centre, Queen's University Belfast, 97 Lisburn Road, Belfast, BT9 7BL, United Kingdom.

${ }^{3}$ School of Pharmacy and Pharmaceutical Sciences, Ulster University, SAAD Building, Cromore Road, Coleraine, BT52 1SA, United Kingdom.

${ }^{4}$ Maynooth University Department of Biology, Maynooth University, Maybooth, Co. Kildare, Ireland.

* Authors for correspondence: Tel.: +44 (0) 2890972251 (RFD); 44 (0) 2077535868 (GRW).Email: r.donnelly@qub.ac.uk (RFD); g.williams@ucl.ac.uk (GRW)

Keywords Microneedle, transdermal drug delivery, electrohydrodynamic atomisation, ovalbumin, PLGA, microparticles 
Abstract

Transdermal delivery of biological therapeutics is emerging as a potent alternative to intravenous or subcutaneous injections. The latter come with major challenges including patient discomfort, the necessity for trained personnel, specialized sharps disposal, and risk of infection. Microneedle (MN) technology circumvents many of the abovementioned challenges, delivering biological material directly into the skin and allowing sustained release of the active ingredient both in animal models and in humans. This study describes the use of electrohydrodynamic atomization (EHDA) to coat ovalbumin (OVA)-encapsulated PLGA nanoparticles onto hydrogel-forming MN arrays. The particles showed extended release of OVA over ca. 28 days. Microscopic analysis demonstrated that EHDA could generate a uniform particle coating on the MNs, with $30 \%$ coating efficiency. Furthermore, the coated MN array manifested similar mechanical characteristics and insertion properties to the uncoated system, suggesting the coating should have no detrimental effects on the application of the MNs. The coated MNs resulted in no significance increase in anti-OVA specific IgG titres in C57BL/6 mice in vivo as compared to the untreated mice (paired t-test, $p>0.05$ ) indicating that the formulations are non-immunogenic. The approach of using EHDA to coat a MN array thus appears to have potential as a novel non-invasive protein delivery strategy. 


\section{Introduction}

Protein and peptide therapeutics have become increasingly widely adopted in the clinic over recent years because of their high specificity and potency. The major route of administration is via parenteral delivery such as subcutaneous (SC), intramuscular (IM), or intravenous (IV) injection. ${ }^{1,2}$ However, these current approaches are problematic: whilst IV injection maximizes bioavailability, it is not suitable for self-administration. SC injection can be performed on oneself, but the results are highly variable owing to differences in technique and competence between users. Moreover, both approaches can be painful and daunting to patients, and thus compliance can be low. ${ }^{3}$ Alternative approaches to deliver therapeutic biologic payloads into the body, ideally with sustained release profiles, are thus much sought after.

One such approach involves the use of microneedle (MN) arrays. These are made of submillimeter needle structures fabricated using polymeric materials and mounted on a supporting baseplate. They offer the prospect of self-application by patients, reducing the burden of cost associated with trained health care professionals in low-resource settings. A number of MN types are discussed within the literature, but hydrogel-forming MNs are of particular interest. ${ }^{4,5}$ In the dry state, such MNs are hard and can be applied to the skin using gentle pressure. They penetrate the stratum corneum, inserting into the dermal tissues below, and swell upon taking up interstitial skin fluid. MN technology has been shown to deliver a range of biologics, such as insulin, ${ }^{5,6}$ ovalbumin, ${ }^{7}$ and monoclonal antibodies. ${ }^{8}$ However, MNs have also been particularly widely explored in the vaccine field, and their ability to deliver antigenic material directly to antigen presenting cells (APCs) within the skin and enhance immune responses is well established. ${ }^{9,10}$ This is potentially a major problem for the delivery of therapeutic biologics: an immune response to such payloads would obviate their benefits and could be dangerous to the patient.

Proteins can be incorporated into a MN matrix during or after the production process. ${ }^{11,12}$ One approach to the former is to mix the protein with the polymer solution before the $\mathrm{MN}$ are cast from a mould. ${ }^{13}$ This method potentially exposes the proteins to physical stress from UV, organic solvents, and heat however, which can lead to degradation or destabilization of the encapsulated protein, thus diminishing the protein activity. ${ }^{14}$ To avoid this, hydrogel-forming MNs are often used in combination with a protein reservoir, ${ }^{15}$ but this can result in significant 
wastage of the biologic. ${ }^{11,13}$ Another approach is to coat the preformed MNs with a protein layer mixed with a coating polymer solution, ${ }^{16}$ however this could diminish the protein activity. ${ }^{14}$

Electrohydrodynamic atomisation (EHDA) is a technology used to produce particulates through the application of electrical energy to polymer solutions. ${ }^{17}$ Because it obviates the need to apply heat to solidify a solution, EHDA has been explored to develop novel formulations for a wide range of biologics ranging from peptide oligomers to proteins and even cells. ${ }^{18-20}$ EHDA encapsulation processes can also preserve the structural integrity of the loaded proteins, thus maintaining their biological activities. ${ }^{21}$ Further, in contrast to other production methods, EHDA can deposit particles directly onto surfaces, creating microstructures. ${ }^{22}$ This has a number of benefits in terms of encapsulating the protein in a delivery system which can be designed to tune and control drug release to meet a desired therapeutic goal. ${ }^{23}$ The technique has been widely applied for tissue engineering, but has yet to be exploited for microneedle coating. ${ }^{24}$

In this work, we report the development of an EHDA coating process for hydrogel forming MNs. We use this to construct a novel protein delivery system where the MNs are coated with poly(lactide-co-glycolide) (PLGA) microparticles loaded with the model protein ovalbumin (OVA). PLGA is a biocompatible and biodegradable polymer approved for therapeutic devices providing sustained release. Its use here should give extended release of OVA, and by varying the ratio of lactide to glycolide in the particles the release profile can be tuned. The MN approach allows minimally invasive implantation of OVA loaded particles, which can reduce injection frequency and thereby improve patient acceptance. The coated MNs were characterized in detail, and their drug release properties and potential immunogenicity explored in detail both in vitro and in vivo.

\section{Materials and methods}

\section{$2.1 \quad$ Materials}

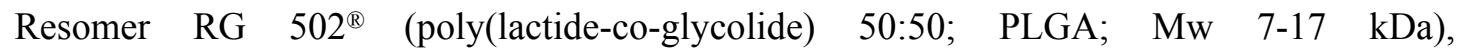
polyvinylpyrrolidone (PVP; $360 \mathrm{kDa}$ ), poly(ethylene glycol) (PEG; $10 \mathrm{kDa}$ ), 2,2,2,trifluoroethanol (TFE), ovalbumin (OVA), resazurin sodium salt, sodium chloride, dimethyl sulfoxide (DMSO), EDTA, lipopolysaccharide from E coli O11:B4 (LPS), InstantBlue ${ }^{\mathrm{TM}}$, 


\subsection{Methods}

\subsubsection{PVP film casting}

A $10 \% \mathrm{w} / \mathrm{v}$ PVP solution in ethanol (ca. $10 \mathrm{~mL}$ ) was slowly poured into a $90 \mathrm{~mm}$ diameter petri dish with care taken to ensure no air bubbles formed. The PVP films were left to dry overnight at $30^{\circ} \mathrm{C}$, and $1 \times 1 \mathrm{~cm}^{2}$ sections were then cut.

\subsubsection{EHDA optimization}

Resomer RG $502^{\circledR}$ PLGA was dissolved in TFE, with stirring at room temperature until complete dissolution. Four PLGA solutions were prepared with varied concentrations: 2\%, 4\%, $6 \%$ and $8 \% \mathrm{w} / \mathrm{v}$. The PLGA solutions were carefully loaded into $1 \mathrm{~mL}$ disposable plastic 
syringes (Terumo, UK) to prevent bubble formation. The syringe was then mounted on a 789100C syringe pump (Cole Parmer, UK). A 20G stainless steel dispensing needle (inner diameter $0.61 \mathrm{~mm}$; Nordson EFD, UK) was attached to the tip of the syringe. The positive electrode of a HCP 35-35000 high voltage DC power supply (FuG Elektronik, Germany) was then attached to the spinneret. A $1 \times 1 \mathrm{~cm}^{2}$ aluminum collector plate was fixed to the tip of a second $20 \mathrm{G}$ stainless steel needle, mounted on a height-adjustable stand.

A cast PVP film was placed on the coating plate and the grounded electrode was clipped on the needle. The experimental set-up is shown in Figure S1 (Supporting Information). The PLGA solution was directly electrosprayed onto the PVP film for 30 min using the parameters given in Table S1. The coated films were stored at room temperature prior to further analysis.

\subsubsection{Preparation and characterization of OVA/PLGA particles}

\subsubsection{Electrospraying}

PLGA elecspraying solutions were prepared in a safety cabinet under sterile conditions. The EHDA chamber was wiped with $70 \%$ alcohol before work began, and all other equipment was either procured sterile or autoclaved. FITC-OVA solution (prepared as detailed in the Supporting Information and characterised in Figure S2; $c$ a. $10 \mathrm{mg} / \mathrm{mL}, 1.0 \mathrm{~mL}, 10 \mathrm{mg}$ ) was centrifuged using a Vivaspin $6^{\circledR}$ centrifugal concentrator (MWCO $30 \mathrm{kDa}$; VWR International, UK) at $4000 \mathrm{rpm}$ for $15 \mathrm{~min}$ at $9{ }^{\circ} \mathrm{C}$, to obtain a concentrated solution $(c a .100 \mathrm{mg} / \mathrm{mL}, 0.1$ $\mathrm{mL})$. The concentrated fluorescent protein $(0.1 \mathrm{~mL})$ was then added to an $8 \% \mathrm{w} / \mathrm{v}$ PLGA solution in TFE $(1.0 \mathrm{~mL})$, followed by Tween $20(1.0 \mu \mathrm{L})$, and gently mixed until the mixture became homogenous. The resultant solution was loaded into a disposable syringe. A sterile aluminum cup (diameter $38 \mathrm{~mm}$, height $19 \mathrm{~mm}$ ) was filled with sterile deionized (DI) water $(2.5 \mathrm{~mL})$ and the edge of the cup connected to the grounded electrode. Electrospraying was performed for $5 \mathrm{~h}$ using the optimized parameters obtained above (a flow rate of $0.2 \mathrm{~mL} / \mathrm{h}$, collecting distance of $10 \mathrm{~cm}$, and applied voltage of $12 \mathrm{kV}$ ).

After the electrospraying process, the FITC-OVA/PLGA particle suspension was collected and sonicated for $30 \mathrm{~min}$ at room temperature in a water bath to redisperse the particles. The FITCOVA/PLGA particles were lyophilized by freezing at $-60^{\circ} \mathrm{C}$ for $2 \mathrm{~h}$ and subsequently dried at $-20{ }^{\circ} \mathrm{C}$ for 3 days (primary drying). Thereafter, the temperature was increased to $20^{\circ} \mathrm{C}$ for $2 \mathrm{~h}$ 
for secondary drying before sample collection. The lyophilized OVA/PLGA particles were weighed to determine the product yield, which is presented as a percentage of the mass of lyophilized particles over the theoretical maximum mass of particles $(90 \mathrm{mg})$.

\subsubsection{Particle characterization}

\section{Scanning electron microscopy (SEM):}

Electrosprayed FITC-OVA/PLGA particles $(c a .1 \mathrm{mg}$ ) were mounted onto aluminium SEM stubs (TAAB Laboratories, UK) with carbon-coated double-sided tape. The samples were then coated with a $20 \mathrm{~nm}$ gold sputter (Q150T, Quorum, UK) under argon. A Quanta 200F field emission (FEG) SEM (FEI, the Netherlands) connected to a secondary electron detector was used to generate SEM images of the materials. The size of the particles in the samples was measured using the ImageJ software version 1.49 (National Institutes of Health, USA).

\section{Fourier transform infrared spectroscopy (FTIR)}

FTIR spectra were obtained using a Spectrum 100 spectrometer (Perkin Elmer, USA). Data were collected over the wavenumber range from $650-4000 \mathrm{~cm}^{-1}$, with resolution $1 \mathrm{~cm}^{-1}$ and 4 scans obtained per sample.

\section{Differential scanning calorimetry (DSC)}

DSC analyses were performed on a Q2000 instrument (TA Instruments, UK). Samples ( $c a$. 1.0 $\mathrm{mg}$ ) were loaded in T130425 Tzero aluminium pans (TA instruments, UK) and hermetically sealed with pin-holed aluminium lids. Nitrogen gas was purged through the instrument at a flow rate of $50 \mathrm{~mL} / \mathrm{min}$ throughout the process. Sample pans were typically heated from 0 to $150{ }^{\circ} \mathrm{C}$ at $10{ }^{\circ} \mathrm{C} / \mathrm{min}$. For modulated temperature DSC (MDSC), a heating range from $0-150$ ${ }^{\circ} \mathrm{C}$, rate of $3{ }^{\circ} \mathrm{C} / \mathrm{min}$, frequency of $60 \mathrm{~s}$, and amplitude of $1{ }^{\circ} \mathrm{C}$ were used.

\section{X-ray diffraction (XRD)}

Electrosprayed particles ( $c a .1 \mathrm{mg}$ ) were mounted on an aluminum sample holder and XRD diffraction patterns collected using a MiniFlex 600 diffractometer (Rigaku, Japan) supplied with $\mathrm{Cu}-\mathrm{K} \alpha$ radiation $\left(\lambda=1.5418 \AA\right.$ ). Samples were scanned at $0.5^{\circ} / \mathrm{min}$ over the $2 \theta$ range 3$50^{\circ}$, at $40 \mathrm{kV}$ and $15 \mathrm{~mA}$. 


\section{Zeta potential measurement}

Zeta potential measurements were performed using a Zetasizer Nano ZS instrument (Malvern Instruments, UK). Approximately $1.0 \mathrm{mg}$ of sample was suspended in DI water $(>18.2 \mathrm{~m} \Omega, 1.0$ $\mathrm{mL}$, viscosity $(\eta) 0.8872 \mathrm{cP}$, refractive index (RI) 1.330 , dielectric constant 78.5 ) and loaded into a DTS1070 disposable folded capillary polystyrene cell (Malvern Instruments Ltd., UK) which had been pre-washed with absolute ethanol and dried prior to use. The measurements were performed at $25^{\circ} \mathrm{C}$. Zeta potentials were calculated using Smoluchowski's equation with a Henry's function $(\mathrm{f}(\mathrm{K} \alpha))$ of 1.50 .

\subsubsection{Encapsulation efficacy}

The encapsulation efficacy of the FITC-OVA/PLGA particles was quantified as previously described. ${ }^{25}$ Briefly, $1 \mathrm{mg}$ of the particles was extracted with $0.5 \% \mathrm{w} / \mathrm{v}$ sodium dodecyl sulfate (SDS) in sodium hydroxide $(100 \mathrm{mM}, 1.0 \mathrm{~mL})$ under shaking at $100 \mathrm{rpm}$ at room temperature overnight. The supernatants were then collected, filtered through $0.22 \mu \mathrm{m}$ Millex-GP syringe filter units (Fisher Scientific, UK), and 10-fold diluted with DI water prior to determining the protein content using the MicroBCA ${ }^{\mathrm{TM}}$ assay according to the manufacturer instructions. The encapsulation efficiency is presented as the percentage of FITC-OVA extracted from the particles, compared to the maximum theoretical amount of FITC-OVA which could have been incorporated $(111 \mu \mathrm{g})$.

\subsubsection{In vitro release}

In vitro drug release from the labelled FITC-OVA/PLGA particles was determined using a shaking method previously reported. ${ }^{26}$ Approximately $10 \mathrm{mg}$ of the particles were suspended in PBS buffer $(30.0 \mathrm{~mL}, \mathrm{pH} 7.4)$, supplemented with $0.05 \% \mathrm{w} / \mathrm{v}$ sodium azide in a $50 \mathrm{~mL}$ beaker covered with ParafilmM ${ }^{\circledR}$ to prevent evaporation of the release medium. The dissolution study was performed in a shaker incubator at 52 strokes/min and $32{ }^{\circ} \mathrm{C}$, to mimic the skin temperature. ${ }^{27}$ Release aliquots $(3.0 \mathrm{~mL})$ were collected from the release medium periodically and replenished with an equal volume of preheated fresh medium.

The collected aliquots were filtered with $0.22 \mu \mathrm{m}$ Millex-GP syringe filter units (Fisher Scientific, UK) and the protein content quantified using the MicroBCA ${ }^{\mathrm{TM}}$ protein assay. The results are presented as percentage cumulative release versus time, as given in Equation 1. The 
release kinetics were mathematically modeled using the zero-order, first-order, KorsmeyerPeppas, and Higuchi models..$^{28}$

$$
\% \text { Cumulative protein release }=\frac{M_{t}}{M_{\infty}} \times 100
$$

\section{Equation 1}

where $M_{t}$ is the cumulative amount of drug release at time $t$ and $M_{\infty}$ is the actual protein loading.

\subsubsection{Cell experiments}

\section{In vitro MoDC FITC-OVA/PLGA particle uptake}

Monocyte derived dendritic cells (MoDC) were obtained from human blood samples by isolating $\mathrm{CD}_{1} 4^{+}$monocytes and stimulating them with GM-CSF and IL-4 (see protocols in the Supporting Information for full details). MoDC were seeded $\left(1 \times 10^{5}\right.$ cells, $0.1 \mathrm{~mL} /$ well $)$ in a 96-well flat bottomed plate and incubated at $37{ }^{\circ} \mathrm{C} / 5 \% \mathrm{CO}_{2}$ for $3 \mathrm{~h}$ before each experiment. Approximately $45 \mathrm{mg}$ of the FITC-OVA/PLGA particles (5 mg FITC-OVA theoretical loading) were resuspended in complete RPMI $(0.5 \mathrm{~mL})$. The particle suspension was sonicated at room temperature for $15 \mathrm{~min}$ to redisperse the particles. MoDCs were then treated with the particle suspension $(0.1 \mathrm{~mL})$ or controls as shown in

Table 1. Experiments were performed for $24 \mathrm{~h}$ at $37{ }^{\circ} \mathrm{C}$ and $5 \% \mathrm{CO}_{2}$. After $24 \mathrm{~h}$ incubation, the microplates were centrifuged at $1200 \mathrm{rpm}$, for $5 \mathrm{~min}$ at $4{ }^{\circ} \mathrm{C}$. The MoDCs in each well were then washed three times with cold washing buffer and resuspended in complete RPMI medium $(0.2 \mathrm{~mL} /$ well). The cell morphology and particle uptake were observed under an EVOS XL Cell Imaging System digital inverted microscope (ThermoFisher, UK). The Alamar Blue viability assay was performed by adding $5 \mathrm{mM}$ sodium rezasurin in complete medium (40.0 $\mu \mathrm{L})$ to each well. The microplates were incubated at $37{ }^{\circ} \mathrm{C} / 5 \% \mathrm{CO}_{2}$ for $4 \mathrm{~h}$ and the fluorescence optical densities at $555 \mathrm{~nm}$ excitation / $585 \mathrm{~nm}$ emission monitored using a SpectraMax M2 microplate reader (Molecular Devices, UK). Cell viability was expressed as a percentage where untreated cells were taken to have $100 \%$ viability.

In a separate set of experiments performed under the same conditions, flow cytometry (FACS) was employed to quantify the uptake of the FITC-OVA particles after $24 \mathrm{~h}$ incubation, by 
determining the median fluorescence intensity (MFI) and \% positive cells in the FITC channel. The measured MFI is presented as an expression ratio calculated by dividing the MFI of the treated group by the value obtained for untreated cells. The expression of CD86 was also determined by FACS, using a PE-labelled antibody.

Table 1 Details of the conditions used to probe FITC-OVA/PLGA particle uptake by MoDCs.

\begin{tabular}{|l|l|}
\hline \multicolumn{1}{|c|}{ ID } & \multicolumn{1}{|c|}{ Treatment } \\
\hline LPS & Diluted LPS in complete RPMI $(100 \mathrm{ng} / \mathrm{mL})$ (positive control) \\
\hline P1 & FITC-OVA/PLGA particle $(9.0 \mathrm{mg}$ particles in 0.1 mL complete RPMI/well) \\
\hline P2 & A 100-fold dilution of the P1 suspension in complete RPMI $(0.1 \mathrm{~mL} /$ well $)$ \\
\hline S1 & $\begin{array}{l}\text { FITC-OVA in complete RPMI (1.0 mg FITC-OVA in 0.1 mL complete RPMI/ } \\
\text { well })\end{array}$ \\
\hline S2 & $\begin{array}{l}\text { A 100-fold dilution of the S1 solution in complete RPMI }(10.0 \mu \mathrm{g} \text { FITC-OVA in } \\
0.1 \mathrm{~mL} \text { RPMI/well })\end{array}$ \\
\hline PLGA & PLGA powder in complete RPMI (8 mg PLGA in 0.1mL/ well $)$ \\
\hline
\end{tabular}

\subsubsection{OVA/PLGA particle coated MNs}

\subsubsection{Hydrogel-forming MN production}

A stock solution of Gantrez ${ }^{\circledR}$ S-97 $(40 \% \mathrm{w} / \mathrm{w})$ was diluted with deionized water and mixed with PEG $(7.5 \% \mathrm{w} / \mathrm{w})$ and sodium carbonate $(3 \% \mathrm{w} / \mathrm{w})$ until bubble formation had ceased. After degassing (centrifugation at $3500 \mathrm{rpm}$ for $15 \mathrm{~min}$ ), the formulation was dispensed, using manual syringing, onto female silicone micromoulds. The latter were prepared by laser drilling to create arrays of $19 \times 19$ needles of depth and base width $500 \mu \mathrm{m}$ and $300 \mu \mathrm{m}$ respectively, interspaced by $50 \mu \mathrm{m}$ between needle bases. Positive pressure atmospheres of 3 bar housed within a steel vessel were used to ensure the formulation filled each needle tip fully. MN arrays were left to dry for $48 \mathrm{~h}$ at room temperature and subsequently cross-linked by heat $\left(80^{\circ} \mathrm{C}\right)$ for $24 \mathrm{~h}$.

\subsubsection{OVA/PLGA particle coating on hydrogel MN}

Hydrogel-forming MNs were coated with OVA/PLGA particles using an OVA-PLGA solution containing OVA in DI water $(150 \mathrm{mg} / \mathrm{mL}, 0.02 \mathrm{~mL}), 8 \% \mathrm{w} / \mathrm{v}$ Resomer ${ }^{\circledR}{ }^{R G} 502$ in TFE 
The insertion performance of MNs was also evaluated using an Instron universal testing instrument, Model 5567 (Instron Ltd., USA). The Parafilm $\mathrm{M}^{\circledR}$ platform was placed on the solid support of the Instron instrument. MNs were placed on top of the film membrane, and the back of the array was mounted to the solid support. A $100 \mathrm{~N}$ static load was lowered onto the membrane at a rate of $0.5 \mathrm{~mm} / \mathrm{s}$, compressing the MNs until a target force of $50 \mathrm{~N}$ was achieved. Subsequently, the static load was moved upward back to the reference point. Forces were held for $30 \mathrm{~s}$ in each test. Force (load) - displacement curves were constructed, and the discontinuous point in the curve demonstrated the force of injection $\left(f_{i}\right)$. The deposition of the OVA/PLGA particles in the Parafilm $\mathrm{M}^{\circledR}$ skin mimicking platform was examined under the EVOS XL Cell Imaging System using the GFP fluorescence filter.

\subsubsection{MN penetration analyses}

MN penetration was determined using optical coherence tomography (OCT). OCT images were recorded using an EX1301 OCT Microscope (Michelson Diagnostics Ltd., UK). This has a laser center wavelength of $1305.0 \pm 15.0 \mathrm{~nm}$, facilitating real-time high-resolution imaging $(7.5$ $\mu \mathrm{m}$ lateral and $10.0 \mu \mathrm{m}$ vertical resolution). The MN samples were scanned at a frame rate of up to $15 \mathrm{~B}$-scans (2D cross-sectional scans) per second (scan width $=2.0 \mathrm{~mm}$ ) and analysed using the imaging software, ImageJ1 (National Institutes of Health, USA). 


\subsubsection{In vivo experiments}

\subsubsection{In vivo immunogenicity studies}

Approval for animal experiments was obtained from the Committee of the Biological Services Unit, Queen's University Belfast. All in vivo experiments were conducted according to the policy of the federation of European Laboratory Animal Science Associations and the European Convention for the protection of vertebrate animals used for experimental and other scientific purposes, with implementation of the principles of the 3Rs. Coated MNs were applied to the ear pinnae of 8 week old female C57BL/6 mice ( $\mathrm{n}=5$; Charles River Laboratories, UK), and held in place for 5 min using adhesive tape (3M Science, USA). The MNs were left in place for $24 \mathrm{~h}$ post-administration, after which the MN arrays had swollen and dissolved. The application of MNs was repeated at day 0,14 , and 28 days. In the control group, mice were treated with an intraperitoneal dose of $100 \mu \mathrm{g}$ OVA on day 0,14 , and 28 .

\subsubsection{Extraction of serum}

For blood withdrawals, tail prick procedures were employed. Tail veins were dilated using heat $\left(38^{\circ} \mathrm{C}\right.$ for $<5 \mathrm{~min}$ ) and a $25 \mathrm{G}$ needle used to prick the tip of the tail. Blood samples (20.0 $\left.\mu \mathrm{L}\right)$ were collected into non-heparinized serum collection microtubes. The blood was heated to 37 ${ }^{\circ} \mathrm{C}$ for $60 \mathrm{~min}$ to promote coagulation, and centrifuged (2000 rpm for $15 \mathrm{~min}$, at $4{ }^{\circ} \mathrm{C}$ ). The supernatant (serum) was then stored at $-80^{\circ} \mathrm{C}$ until required for analysis.

\subsubsection{Anti-OVA IgG specific enzyme linked immunosorbent assay (ELISA)}

Serum samples were analysed for OVA-specific IgG antibodies by ELISA (ELISA Genie, Ireland). Analysis was carried out according to the manufacturer's instructions. Antibody titres were determined through spectroscopy with absorbance recorded using a FluoStar Omega microplate reader (BMG Labtech, Germany) at $450 \mathrm{~nm}$. 


\subsubsection{Statistical analysis}

Quantitative data are presented as mean \pm standard deviation (S.D.). Statistical analysis was performed using Microsoft Excel or GraphPad Prism (2016). Statistical tests were carried out as described in the text and $p<0.05$ used as an indicator of significance throughout.

\section{Results}

\subsection{Opimization of EHDA coating}

An initial optimization of the processing parameters for EHDA coating was undertaken by varying the polymer concentration and the flow rate (Table S1). SEM images (Figure S3) revealed a profound effect on particle morphology, with irregular particles obtained using a $2 \%$ $\mathrm{w} / \mathrm{v}$ solution of PLGA and a mixture of fibres and particles seen at 4 and $6 \% \mathrm{w} / \mathrm{v}$. Higher concentrations of $8 \%$ gave fibres. A further optimization of 6 and $8 \% \mathrm{w} / \mathrm{v}$ solutions revealed more particles to be produced at low flow rates and the lower concentration (Figure S4). The particle morphology suggested that suitable conditions to produce particles were concentrations from $6 \%$ to $8 \% \mathrm{w} / \mathrm{v}$ PLGA and a flow rate of $0.2 \mathrm{~mL} / \mathrm{h}$. However, a higher polymer concentration was preferable to ensure compactness of the produced particles. ${ }^{30}$ Therefore, process conditions of $8 \% \mathrm{w} / \mathrm{v}$ PLGA and $0.2 \mathrm{~mL} / \mathrm{h}$ were used for PLGA coating.

\subsection{FITC-OVA/PLGA particles}

\subsubsection{Morphology}

FITC-OVA-loaded PLGA particles were first produced to determine their properties prior to MN array coating. A solution comprising $10 \mathrm{mg}$ FITC-OVA loaded in 8\% w/v PLGA in TFE $(1.0 \mathrm{~mL})$ was used, with a flow rate of $0.2 \mathrm{~mL} / \mathrm{h}$, a spinneret to collector distance of $10 \mathrm{~cm}$, and voltage of $12 \mathrm{kV}$ employed as the processing parameters. The addition of FITC-OVA was not found to affect the electrospraying parameters, and thus the optimal conditions identified for PLGA could be employed here. PLGA particles were electrosprayed into DI water to enhance the yield. Since PLGA is not soluble in water, the particles generated floated on the surface of the water, thus facilitating particle collection. SEM images in Figure1a-c show that monodisperse OVA/PLGA particles with size of $777 \pm 138 \mathrm{~nm}$ were produced. However, the particles appeared to be aggregated rather than existing as discrete entities. This is in line with previous results, ${ }^{31}$ and is due to the hydrophobicity and poor wetting properties of PLGA. 
Nonetheless, the production yield was remarkably high at $71.8 \pm 6.2 \%(\mathrm{n}=4)$. Some deposition of particles on the edge of the aluminum container was observed (data not shown), which contributed to the production loss.

\subsubsection{Particle characterization}

The inclusion of FITC-OVA in the PLGA particles was verified using FTIR (Figure1d). PLGA shows absorption peaks at $1752 \mathrm{~cm}^{-1}(\mathrm{C}=\mathrm{O}$ stretching $)$ and 1270,1174 and $1084 \mathrm{~cm}^{-1}$ (asymmetric and symmetric C-O vibrations). These are characteristic peaks for ester functional groups. The spectrum of PLGA is consistent with results reported elsewhere. ${ }^{32,33}$ Three main peaks at 3282, 1654 and $1529 \mathrm{~cm}^{-1}$ were observed in lyophilized FITC-OVA; these correspond to the stretching vibrations of $\mathrm{OH}$ groups (water adsorption), the amide $\mathrm{I}$ band $(\mathrm{C}=\mathrm{O}$ stretching) and the amide II band (N-H bending and C-N stretching). ${ }^{34}$ These features are typical of the IR spectra of proteins. ${ }^{35-38}$ Absorption peaks of FITC might be expected between $1400-1500 \mathrm{~cm}^{-}$

${ }^{1}$, corresponding to aromatic ring stretching vibrations. ${ }^{39}$ However, the FITC signal is obscured by the protein signals, which are both strong and complex in this region. The FITC-OVA/PLGA particles exhibited the IR bands of both PLGA and OVA, including the ester functional groups of PLGA $\left(1084,1174,1270\right.$, and $\left.1752 \mathrm{~cm}^{-1}\right)$ and the protein amide region (1534 and 1654 $\mathrm{cm}^{-1}$ ). This indicates the successful encapsulation of OVA by EHDA.

The physical form of the components in the particles was explored by DSC and XRD (Figures S5 - S7). PLGA, FITC-OVA and the FITC-OVA/PLGA particles are all found to be amorphous, with no evidence for any crystalline materials present. The zeta potential of the particles in DI water at $25{ }^{\circ} \mathrm{C}$ was found to be $-27.3 \pm 3.5 \mathrm{mV}(\mathrm{n}=3)$. The negatively charged particle surfaces can be attributed to the carboxylate groups of PLGA, which can be expected to be ionized at neutral $\mathrm{pHs} .{ }^{40}$

\subsubsection{Drug loading and release}

The encapsulation efficiency of the PLGA particles, as quantified from a MicroBCA assay, was $95.6 \pm 5.9 \%(\mathrm{n}=4)(c a .105 \mu \mathrm{g}$ FITC-OVA / mg particles). This high OVA encapsulation can be ascribed to the compatibility of OVA with the polymer, as a result of hydrophobic interactions between OVA and PLGA. ${ }^{41}$ In vitro release studies were performed using the shaking method, commonly employed to study the release kinetics of microparticles. ${ }^{26,39-40}$ The cumulative release and concentration profiles of the FITC-OVA/PLGA particles are given in 
The release profiles of the PLGA particles were fitted with mathematical models to elucidate the release mechanism of FITC-OVA. The kinetic parameters obtained are given in

Table 2. The release profile of the particles was best fitted with the Korsmeyer-Peppas release model (Figures S8 - S11; $\mathbf{R}^{2}=0.97$ ). An exponent of 0.21 indicates that the OVA release mechanism was dominated by Fickian diffusion. ${ }^{44}$

Table 2 Release kinetics of the FITC-OVA loaded PLGA particles

\begin{tabular}{|l|l|}
\hline Release model and parameters & $\begin{array}{l}\text { Values obtained with FITC- } \\
\text { OVA/PLGA particles }\end{array}$ \\
\hline$k_{0}$ & 0.78 day $^{-1}$ \\
$t_{1 / 2}$ & 56.87 days \\
$\mathrm{R}^{2}$ & 0.84 \\
\hline First-order release & \\
$k_{1}$ & 0.05 day $^{-1}$ \\
$t_{1 / 2}$ & 12.91 days $^{2}$ \\
$\mathrm{R}^{2}$ & 0.86 \\
\hline Higuchi & \\
$k_{H}$ & $168.68 \mu \mathrm{g} \mathrm{day}^{-1 / 2}$ \\
$\mathrm{R}^{2}$ & 0.91 \\
\hline Korsmeyer-Peppas & \\
\hline
\end{tabular}


Abbreviations: $k_{0}=$ zero-order rate constant, $k_{l}=$ first-order rate constant, $k_{H}=$ Higuchi rate constant, $k_{k p}=$ Korsmeyer-Peppas rate constant, $n=$ release exponent of the KorsmeyerPeppas model, $R^{2}=$ correlation coefficient, $t_{1 / 2}=$ half-life

\subsubsection{In vitro experiments}

There is a clear reduction of CD14 expression after monocytes have been treated with GMCSF and IL-4 (see Figure S12), confirming their differentiation into immature DCs. The uptake of FITC-OVA loaded PLGA particles was determined after incubation with MoDCs, using a fluorescence digital microscope and FACS. Before assays, the cells were washed with cold buffer to prevent any further particle uptake. ${ }^{45}$ This means that the excess particles and any FITC-OVA left in solution were removed before analyses, and any observed fluorescence corresponds to intracellular fluorescence from uptake. Figure 3 shows the MoDC morphology after exposure to the particles. All FITC-OVA treated cells (P1, P2, S1, S2) exhibited round morphologies similar to untreated cells (Figure 3a), while LPS-treated cells showed more branched morphology and aggregation, suggesting the development of mature MoDC (Figure 3b). All FITC-OVA treated cells showed intracellular fluorescence after $24 \mathrm{~h}$ incubation, indicating FITC-OVA uptake (see Figure 3c-f). The morphology of the particles visible in this experiment (Figure 3g) was consistent with the SEM data, in that the PLGA particles formed aggregates. The MoDC tended to adhere to the particle aggregates in the particle-treated groups, while the cells appeared more spread out upon treatment with a FITC-OVA solution (Figure 3h and i). FITC-OVA uptake is confirmed by a quantitative flow cytometric assessment (Figure S13). The FITC positive populations from all treatment groups were significantly higher than the untreated cells (ANOVA with post-hoc Tukey test; $p<0.001$ ), except in the case of the P2 treatment group (with a low concentration of FITC-OVA/PLGA particles). The percentage positive population followed the trend of the MFI ratio, in that the uptake was concentration dependent and there was no significant difference between the solution and particle formulations in the case of S1 and P1. Following $24 \mathrm{~h}$ incubation with the formulations, the expression of co-stimulatory CD86 was evaluated to determine any potential immunomodulatory activity of the FITC-OVA/PLGA particles (Figure S14). These experiments revealed that the particles have no immunostimulatory properties, with no elevation in CD86 levels noted. 


\subsection{OVA/PLGA coated hydrogel MNs}

\subsubsection{MN array formulation and coating}

Hydrogel-forming MNs were successfully fabricated as previously described. ${ }^{11}$ A representative images are given in Figure 5a-b, showing a complete array of 19 x 19 needles (total 361 needles/array), $600 \mu \mathrm{m}$ in height. Figure 5a and c also shows OVA/PLGA particles coated onto the MN array. Rhodamine-B was added to the electrospraying solution to allow visualization of the particles during the coating process, and a homogeneous hue is noted, suggesting an even coating. This is confirmed by the SEM images in Figure 5g-i. The particle deposition was evenly distributed along the tip and shaft of the MNs and the geometry of the needles remained unchanged compared with pre-coating (Figure 5d-h). Moreover, the coating particles were uniform and smooth, with average sizes of $960 \pm 127 \mathrm{~nm}$ (Figure 5i). The coating efficiency was $27.4 \pm 2.5 \%$ (ca. $3 \mathrm{mg}$ of OVA/PLGA particles per array, $\mathrm{n}=4)$. An OVA extraction was also performed to determine the OVA recovery and the mean value was determined to be $129 \pm 45 \mu \mathrm{g}(\mathrm{n}=3)$ on each $\mathrm{MN}$ array.

\subsubsection{Coated-MN insertion and penetration studies}

The insertion of the uncoated and coated MNs was studied to evaluate the effect of particle coating on their mechanical properties. The force of insertion $\left(f_{\mathrm{i}}\right)$ was determined as the discontinuity in the force-displacement curve at the onset of insertion. Figure 6 demonstrates that the $f_{i}$ of the coated MNs was more reproducible than that of the uncoated analogue, with an average value of $c a .17 \pm 0.3 \mathrm{~N}$ and $12 \pm 6.9 \mathrm{~N}$, respectively. However, there was no statistically significant difference between the groups (unpaired t-test; $\mathrm{p}>0.05$ ). 
Moreover, coated MNs were visualized using a light microscope to ensure array integrity, and individual needle heights were measured pre- and post-insertion into ParafilmM ${ }^{\circledR}$. There was no significant difference in needle heights noted $(p<0.05)$, as shown in Figure 7a. MN insertion into ParafilmM ${ }^{\circledR}$ reached the second layer $(>252 \mu \mathrm{m})$ for both coated and uncoated MNs, with $91.6 \pm 7.6 \%$ and $88.2 \pm 7.7 \%$ of the MN penetrating respectively (Figure $7 \mathbf{b}$ ). This is further illustrated with optical coherence tomography images (Figure 7c), which reveal the MNs penetrating into the ParafilmM $^{\circledR}$ layers. Figure 7d displays representative light microscope images of the ParafilmM ${ }^{\circledR}$ layers following $\mathrm{MN}$ removal, allowing the number of holes created to be counted. With the rate limiting layer of the skin, the stratum corneum, approximately $50 \mu \mathrm{m}$ thick, previous studies have demonstrated that $\mathrm{MN}$ insertion past the first ParafilmM ${ }^{\circledR}$ layer is sufficient to penetrate skin in vivo. ${ }^{26}$ Figure $7 \mathbf{e}$ and $\mathbf{f}$ demonstrate that significant amounts of particles were observed on the second layer after insertion, indicating effective particle deposition in the skin.

\subsection{In vivo MN immunogenicity}

Coated and uncoated MN were successfully applied to the dorsal surface of C57BL/6 mice and held in place for $5 \mathrm{~min}$ on day 0,14 , and 28. After MN application the mice did not present with any indication of erythema, redness, or adverse reaction in response to either the coated or uncoated MNs. This is in line with previous reported studies utilizing hydrogel-forming MNs and other MN types. ${ }^{11,12}$ Anti-OVA specific IgG production increased over the 42-day test period when OVA was given IP, with a significant increase in anti-OVA antibody titers noted between the first and second dose (paired T-test, $\mathrm{p}<0.05, \mathrm{n}=5$ ). However, there were no significant increases noted with the coated $\mathrm{MN}$ cohort or the uncoated MN group compared with the untreated mice (paired T-test, $p>0.05, \mathrm{n}=5$ ) upon repeated MN injection (Figure 8). There is therefore no immune response inculcated in response to delivery of the OVA payload using the coated MNs.

\section{Discussion}

One of the challenges associated with developing protein-loaded particles relates to the stability of the encapsulated biologic. Most biological therapeutics are sensitive to physical stress introduced during material handling and biopharmaceutical manufacturing, which often arises during the encapsulation process. ${ }^{46,47}$ In contrast, EHDA permits encapsulation under mild conditions, improving the stability of bioactive molecules such as monoclonal antibodies, ${ }^{21}$ nucleotides, ${ }^{48}$ or even living cells. ${ }^{49}$ This highlights the potential of EHDA as a platform to 
produce particles the transdermal delivery of a protein active ingredient. Combining this coating technique with hydrogel-forming MNs allows for conservation of protein stability whilst achieving targeted, minimally-invasive, delivery directly to the skin.

The underlying purpose of this paper was to demonstrate proof of concept and test the hypothesis that EDHA could be an efficient process for coating MN with protein-loaded particles. The results outlined above present compelling evidence that EHDA can be successfully used to coat hydrogel-forming MN arrays with a high degree of uniformity and reproducibility. Industrial MN manufacturing capabilities continue to improve, and regulatory authorities are compiling comprehensive standards for MN products. These developments are extremely promising for the scale-up, commercialization, and product success of MN-based formulations. Analogous advancements are being made in EHDA, with GMP-standard EHDA processes for pharmaceutical products now possible. ${ }^{50}$ The feasibility and scalability of using EHDA commercially for MN coating thus appears clear.

The in vivo application of coated $\mathrm{MN}$ in C57BL/6 mice provides further evidence in support of using protein-loaded particles coated onto surfaces using EHDA for therapeutic applications. The major challenge for transdermal delivery of protein drugs is potential immunogenicity, because there are abundant APCs in the skin. ${ }^{51}$ Despite the fact that the presence of particles could potentially promote the activation those $\mathrm{APCs}^{52-54}$ and provoke an immune response, we do not see any significant increase in OVA-specific antibodies in vivo. This could be attributed to various factors. A recent study compared dissolving MNs giving fast OVA release with slow release hydrogel-forming MNs, and found the latter generated a stronger immune response. ${ }^{11}$ This observation is consistent with our results, in that the slow release of OVA appears to suppress significant immune stimulation. Moreover, the OVA/PLGA particle aggregates limit local MoDC uptake (see Figure 3g-i) and trafficking to the lymph nodes. This avoids the induction of a significant adaptive immune response ${ }^{55,56}$ even upon repeated injection. This indicates that particle coated $\mathrm{MN}$ formulations such as that developed here could be used to achieve sustained release of a protein active ingredient without any concerns in terms of the patient developing immunity to the drug.

The EHDA coating reported in this work has a number of advantages over other approaches in the literature. First, it leads to highly controlled deposition in comparison to common coating techniques such as dip-coating or spray coating. ${ }^{57}$ Second, the yield produced by EHDA was 
higher than other approaches. For instance, the loading of riboflavin coated on MNs by a multidip coating process was only $1 \mathrm{mg}$ per $10-20 \mathrm{~cm}^{2} \mathrm{MN}$ array, ${ }^{58}$ approximately 30 fold lower than the EHDA approach used in this work ( $3 \mathrm{mg}$ per $1 \mathrm{~cm}^{2}$ array). Similarly, MN coating by inkjet printing gave a maximum loading of $600 \mu \mathrm{g}$ of 5 -fluoruracil/polymer formulation per 1 $\mathrm{cm}^{2} \mathrm{MN}$ array, ${ }^{59} 50$ fold lower than the EHDA method. However, the coating efficiency is relatively low at ca. $30 \%$, which may arise from the small deposition area of the aluminum plate being challenging to target. To improve the deposition yield, other electrical focusing strategies could be employed, such as using a ring electrode to concentrate the electrical field onto the coating substrate. ${ }^{60}$

This study has highlighted a number of additional features worthy of exploration, specifically the impact of MN geometry, needle spacing, and coating thickness. It is well understood that varying the quantity of protein delivered impacts the therapeutic response. As such, lowering the tip-tip space may provide an opportunity to increase coating thickness and drug loading. Further optimization of EHDA coating using multilayers of particles with different properties (e.g. release kinetics) is expected to lead to a wide range of tunable formulations, and will be explored in future work.

\section{Conclusions}

We show in this work the potential of electrohydrodynamic atomization (EHDA) to coat ovalbumin (OVA)-loaded PLGA nanoparticles onto hydrogel-forming microneedle (MN) arrays. The particles showed extended release of OVA over $c a$. 28 days but do not stimulate the activation of cells of immunity. EHDA could generate a uniform particle coating on the MNs, with $c a$. 30\% coating efficiency. The mechanical characteristics of the MNs are unaffected by the coating process. The coated MN did not lead to an increase in anti-OVA specific responses in a murine study in vivo, thereby proving them to be non-immunogenic. This study demonstrates that EHDA is a viable coating technique to coat particles loaded with a protein therapeutic on hydrogel forming MNs, and that the resultant formulations could have significant potential as a novel non-invasive strategy to achieve extended release of biologics.

\section{Acknowledgements}


This work was supported in part by Wellcome Trust Grant Number WT094085MA. The authors gratefully acknowledge Dr Andrew Weston (UCL School of Pharmacy) for assistance with SEM and TEM measurements, and Mr John Frost (UCL School of Pharmacy) for his help with designing and manufacturing equipment for electrospraying.

\section{Data availability}

The raw/processed data required to reproduce these findings cannot be shared at this time as they form part of an ongoing study.

\section{Supporting Information}

Detailed methods for FITC-OVA conjugation, SDS-PAGE experiments, peripheral blood mononuclear cell (PBMC) isolation, and in vitro monocyte derived dendritic cell (MoDC) differentiation. Full details of the optimisation of PLGA particle preparation. Images of the EHDA set up and FITC-OVA conjugation. SEM images of samples prepared in the PLGA particle optimization study. DSC thermograms and XRD patterns for the optimal PLGA/OVA particles, and OVA release data with fits of mathematical models. Flow cytometry data for MoDC experiments. 


\section{References}

(1) Antosova, Z.; Mackova, M.; Kral, V.; Macek, T. Therapeutic Application of Peptides and Proteins: Parenteral Forever? Trends Biotechnol. 2009, 27 (11), 628-635. https://doi.org/10.1016/J.TIBTECH.2009.07.009.

(2) Geraldes, D. C.; Beraldo-de-Araújo, V. L.; Pardo, B. O. P.; Pessoa Junior, A.; Stephano, M. A.; de Oliveira-Nascimento, L. Protein Drug Delivery: Current Dosage Form Profile and Formulation Strategies. J. Drug Target. 2019, 1-17. https://doi.org/10.1080/1061186X.2019.1669043.

(3) De Felice, K. M. Patients Perception of Risks and Benefits of Biologic Therapy. Inflamm. Bowel Dis. 2019. https://doi.org/10.1093/ibd/izz122.

(4) Larrañeta, E.; Lutton, R. E. M.; Woolfson, A. D.; Donnelly, R. F. Microneedle Arrays as Transdermal and Intradermal Drug Delivery Systems: Materials Science, Manufacture and Commercial Development. Mater. Sci. Eng. R Reports 2016, 104, 132.

(5) Chen, X.; Wang, L.; Yu, H.; Li, C.; Feng, J.; Haq, F.; Khan, A.; Khan, R. U. Preparation, Properties and Challenges of the Microneedles-Based Insulin Delivery System. J. Control. Release 2018, 288, 173-188. https://doi.org/10.1016/J.JCONREL.2018.08.042.

(6) Martanto, W.; Davis, S. P.; Holiday, N. R.; Wang, J.; Gill, H. S.; Prausnitz, M. R. Transdermal Delivery of Insulin Using Microneedles in Vivo. Pharm. Res. 2004, 21 (6), 947-952. https://doi.org/10.1023/B:PHAM.0000029282.44140.2e.

(7) Donnelly, R. F.; McCrudden, M. T. C.; Zaid Alkilani, A.; Larrañeta, E.; McAlister, E.; Courtenay, A. J.; Kearney, M.-C.; Singh, T. R. R.; McCarthy, H. O.; Kett, V. L.; Caffarel-Salvador, E.; Al-Zahrani, S.;Woolfson, D.A. Hydrogel-Forming Microneedles Prepared from "Super Swelling" Polymers Combined with Lyophilised Wafers for Transdermal Drug Delivery. PLoS One 2014, 9 (10), e111547. https://doi.org/10.1371/journal.pone.0111547.

(8) Li, G.; Badkar, A.; Nema, S.; Kolli, C. S.; Banga, A. K. In Vitro Transdermal Delivery of Therapeutic Antibodies Using Maltose Microneedles. Int. J. Pharm. 2009, 368 (12), 109-115. https://doi.org/10.1016/j.ijpharm.2008.10.008.

(9) Al-Zahrani, S.; Zaric, M.; McCrudden, C.; Scott, C.; Kissenpfennig, A.; Donnelly, R. F. Microneedle-Mediated Vaccine Delivery: Harnessing Cutaneous Immunobiology to Improve Efficacy. Expert Opin. Drug Deliv. 2012, 9 (5), 541-550.

(10) Kim, Y.-C.; Prausnitz, M. R. Enabling Skin Vaccination Using New Delivery Technologies. Drug Deliv. Transl. Res. 2011, 1 (1), 7-12. https://doi.org/10.1007/s13346-010-0005-z.

(11) Courtenay, A. J.; Rodgers, A. M.; McCrudden, M. T. C.; McCarthy, H. O.; Donnelly, R. F. Novel Hydrogel-Forming Microneedle Array for Intradermal Vaccination in Mice Using Ovalbumin as a Model Protein Antigen. Mol. Pharm. 2019, 16 (1), 118127. https://doi.org/10.1021/acs.molpharmaceut.8b00895.

(12) Rodgers, A. M.; McCrudden, M. T. C.; Vincente-Perez, E. M.; Dubois, A. V.; Ingram, R. J.; Larrañeta, E.; Kissenpfennig, A.; Donnelly, R. F. Design and Characterisation of 
a Dissolving Microneedle Patch for Intradermal Vaccination with Heat-Inactivated Bacteria: A Proof of Concept Study. Int. J. Pharm. 2018, 549 (1-2), 87-95. https://doi.org/10.1016/j.ijpharm.2018.07.049.

(13) Rodgers, A. M.; Cordeiro, A. S.; Kissenpfennig, A.; Donnelly, R. F. Microneedle Arrays for Vaccine Delivery: The Possibilities, Challenges and Use of Nanoparticles as a Combinatorial Approach for Enhanced Vaccine Immunogenicity. Expert Opin. Drug Deliv. 2018, 15 (9), 851-867. https://doi.org/10.1080/17425247.2018.1505860.

(14) Park, J.-H.; Allen, M. G.; Prausnitz, M. R. Polymer Microneedles for ControlledRelease Drug Delivery. Pharm. Res. 2006, 23 (5), 1008-1019. https://doi.org/10.1007/s11095-006-0028-9.

(15) Courtenay, A. J.; McCrudden, M. T. C.; McAvoy, K. J.; McCarthy, H. O.; Donnelly, R. F. Microneedle-Mediated Transdermal Delivery of Bevacizumab. Mol. Pharm. 2018, 15 (8), 3545-3556. https://doi.org/10.1021/acs.molpharmaceut.8b00544.

(16) Andrianov, A. K.; Marin, A.; DeCollibus, D. P. Microneedles with Intrinsic Immunoadjuvant Properties: Microfabrication, Protein Stability, and Modulated Release. Pharm. Res. 2011, 28 (1), 58-65. https://doi.org/10.1007/s11095-010-0133-7.

(17) Williams, G.; Raimi-Abraham, B.; Luo, C. Nanofibres in Drug Delivery, 1st ed.; UCL Press: London, 2018.

(18) Mehta, P.; Haj-Ahmad, R.; Rasekh, M.; Arshad, M. S.; Smith, A.; van der Merwe, S. M.; Li, X.; Chang, M.-W.; Ahmad, Z. Pharmaceutical and Biomaterial Engineering via Electrohydrodynamic Atomization Technologies. Drug Discov. Today 2017, 22 (1), 157-165. https://doi.org/10.1016/j.drudis.2016.09.021.

(19) Sridhar, R.; Lakshminarayanan, R.; Madhaiyan, K.; Amutha Barathi, V.; Lim, K. H. C.; Ramakrishna, S. Electrosprayed Nanoparticles and Electrospun Nanofibers Based on Natural Materials: Applications in Tissue Regeneration, Drug Delivery and Pharmaceuticals. Chem. Soc. Rev. 2015, 44 (3), 790-814. https://doi.org/10.1039/C4CS00226A.

(20) Williams, G. R.; Chatterton, N. P.; Nazir, T.; Yu, D. G.; Zhu, L. M.; Brandford-White, C. J. Electrospun Nanofibers in Drug Delivery: Recent Developments and Perspectives. Ther. Deliv. 2012, 3, 515-533. https://doi.org/10.4155/tde.12.17.

(21) Angkawinitwong, U.; Awwad, S.; Khaw, P. T.; Brocchini, S.; Williams, G. R. Electrospun Formulations of Bevacizumab for Sustained Release in the Eye. Acta Biomater. 2017, 64, 126-136. https://doi.org/10.1016/j.actbio.2017.10.015.

(22) Lavielle, N.; Hébraud, A.; Mendoza-Palomares, C.; Ferrand, A.; Benkirane-Jessel, N.; Schlatter, G. Structuring and Molding of Electrospun Nanofibers: Effect of Electrical and Topographical Local Properties of Micro-Patterned Collectors. Macromol. Mater. Eng. 2012, 297 (10), 958-968. https://doi.org/10.1002/mame.201100327.

(23) Bock, N.; Dargaville, T. R.; Woodruff, M. A. Electrospraying of Polymers with Therapeutic Molecules: State of the Art. Prog. Polym. Sci. 2012, 37 (11), 1510-1551. https://doi.org/10.1016/j.progpolymsci.2012.03.002.

(24) Xie, J.; Rezvanpour, A.; Wang, C.-H.; Hua, J. Electric Field Controlled Electrospray Deposition for Precise Particle Pattern and Cell Pattern Formation. 2010. https://doi.org/10.1002/aic.12198. 
(25) Gupta, R. K.; Chang, A.-C.; Griffin, P.; Rivera, R.; Guo, Y.-Y.; Siber, G. R. Determination of Protein Loading in Biodegradable Polymer Microspheres Containing Tetanus Toxoid. Vaccine 1997, 15 (6-7), 672-678. https://doi.org/10.1016/S0264410X(96)00233-2.

(26) Larrãeta, E.; Stewart, S.; Fallows, S. J.; Birkhäuer, L. L.; McCrudden, M. T. C.; Woolfson, A. D.; Donnelly, R. F. A Facile System to Evaluate in Vitro Drug Release from Dissolving Microneedle Arrays. Int. J. Pharm. 2016, 497 (1-2), 62-69. https://doi.org/10.1016/j.ijpharm.2015.11.038.

(27) Sarmento, B. Concepts and Models for Drug Permeability Studies. In Cell and Tissue based In Vitro Culture Models; Elsevier: Cambridge, UK, 2016.

(28) Dash, S.; Murthy, P. N.; Nath, L.; Chowdhury, P. Kinetic Modeling on Drug Release from Controlled Drug Delivery Systems. Acta Pol. Pharm. 2010, 67 (3), 217-223. https://doi.org/10.1016/S0928-0987(01)00095-1.

(29) Larraneta, E.; Moore, J.; Vicente-Pérez, E. M.; González-Vázquez, P.; Lutton, R.; Woolfson, A. D.; Donnelly, R. F. A Proposed Model Membrane and Test Method for Microneedle Insertion Studies. Int. J. Pharm. 2014, 472 (1-2), 65-73. https://doi.org/10.1016/j.ijpharm.2014.05.042.

(30) Wang, F.; Li, Z.; Tamama, K.; Sen, C. K.; Guan, J. Fabrication and Characterization of Prosurvival Growth Factor Releasing, Anisotropic Scaffolds for Enhanced Mesenchymal Stem Cell Survival/Growth and Orientation. Biomacromolecules 2009, 10 (9), 2609-2618. https://doi.org/10.1021/bm900541u.

(31) Seth, A.; Katti, D. S. A One-Step Electrospray-Based Technique for Modulating Morphology and Surface Properties of Poly(Lactide-Co-Glycolide) Microparticles Using Pluronics ${ }^{\circledR}$. Int. J. Nanomedicine 2012, 7, 5129-5136. https://doi.org/10.2147/IJN.S34185.

(32) D’Avila Carvalho Erbetta, C.; Alves, R. J.; Resende, J. M.; Freitas, R. F. de S.; Sousa, R. G. de. Synthesis and Characterization of Poly(D,L-Lactide-Co-Glycolide) Copolymer. J. Biomater. Nanobiotechnol. 2012, 03 (02), 208-225. https://doi.org/10.4236/jbnb.2012.32027.

(33) Wang, M.; Feng, Q.; Guo, X.; She, Z.; Tan, R. A Dual Microsphere Based on PLGA and Chitosan for Delivering the Oligopeptide Derived from BMP-2. Polym. Degrad. Stab. 2011, 96 (1), 107-113. https://doi.org/10.1016/j.polymdegradstab.2010.10.010.

(34) Baghaei, B.; Jafari, S. H.; Khonakdar, H. A.; Saeb, M. R.; Wagenknecht, U.; Heinrich, G. A Multioptimization Approach to Assessment of Drug Delivery of PLGA Nanoparticles: Simultaneous Control of Particle Size and Release Behavior. Int. J. Polym. Mater. Polym. Biomater. 2015, 64 (12), 641-652. https://doi.org/10.1080/00914037.2014.996714.

(35) Barth, A. Infrared Spectroscopy of Proteins. Biochim. Biophys. Acta 2007, 1767 (9), 1073-1101. https://doi.org/10.1016/j.bbabio.2007.06.004.

(36) Olsztyńska-Janus, S.; Szymborska-Małek, K.; Gąsior-Głogowska, M.; Walski, T.; Komorowska, M.; Witkiewicz, W.; Pezowicz, C.; Kobielarz, M.; Szotek, S. Spectroscopic Techniques in the Study of Human Tissues and Their Components. Part I: IR Spectroscopy. Acta Bioeng. Biomech. 2012, 14 (3), 101-115.

(37) Pikal, M. J.; Rigsbee, D.; Roy, M. L. Solid State Stability of Proteins III: Calorimetric 
(DSC) and Spectroscopic (FTIR) Characterization of Thermal Denaturation in Freeze Dried Human Growth Hormone (HGH). J. Pharm. Sci. 2008, 97 (12), 5122-5131. https://doi.org/10.1002/jps.21386.

(38) Schüle, S.; Friess, W.; Bechtold-Peters, K.; Garidel, P. Conformational Analysis of Protein Secondary Structure during Spray-Drying of Antibody/Mannitol Formulations. Eur. J. Pharm. Biopharm. 2007, 65 (1), 1-9. https://doi.org/10.1016/j.ejpb.2006.08.014.

(39) Zhang, Q.; Jiang, X.; Li, L.; Liu, Q. Cellular Uptake Mechanism and Intracellular Fate of Hydrophobically Modified Pullulan Nanoparticles. Int. J. Nanomedicine 2013, 8, 1825. https://doi.org/10.2147/IJN.S44342.

(40) Yoo, J.-W.; Mitragotri, S.; David Tirrell, by A. Polymer Particles That Switch Shape in Response to a Stimulus. PNAS 2010, 107 (25), 11205-11210.

(41) Mittal, G.; Sahana, D. K.; Bhardwaj, V.; Ravi Kumar, M. N. V. Estradiol Loaded PLGA Nanoparticles for Oral Administration: Effect of Polymer Molecular Weight and Copolymer Composition on Release Behavior in Vitro and in Vivo. J. Control. Release 2007, 119 (1), 77-85. https://doi.org/10.1016/j.jconrel.2007.01.016.

(42) Mi, F.L.; Shyu, S.S.; Lin, Y.M.; Wu, Y.-B.; Peng, C.K.; Tsai, Y.H. Chitin/PLGA Blend Microspheres as a Biodegradable Drug Delivery System: A New Delivery System for Protein. Biomaterials 2003, 24 (27), 5023-5036. https://doi.org/10.1016/S0142-9612(03)00413-7.

(43) Yen, S.Y.; Sung, K. .; Wang, J.J.; Yoa-Pu Hu, O. Controlled Release of Nalbuphine Propionate from Biodegradable Microspheres: In Vitro and in Vivo Studies. Int. J. Pharm. 2001, 220 (1-2), 91-99. https://doi.org/10.1016/S0378-5173(01)00649-4.

(44) Shan, X.; Liu, C.; Li, F.; Ouyang, C.; Gao, Q.; Zheng, K. Nanoparticles vs. Nanofibers: A Comparison of Two Drug Delivery Systems on Assessing Drug Release Performance in Vitro. Des. Monomers Polym. 2015, 18 (7), 678-689. https://doi.org/10.1080/15685551.2015.1070500.

(45) Yoshida, M.; Babensee, J. E. Molecular Aspects of Microparticle Phagocytosis by Dendritic Cells. J. Biomater. Sci. Polym. Ed. 2006, 17 (8), 893-907. https://doi.org/10.1163/156856206777996844.

(46) Abdul-Fattah, A. M.; Truong-Le, V.; Yee, L.; Pan, E.; Ao, Y.; Kalonia, D. S.; Pikal, M. J. Drying-Induced Variations in Physico-Chemical Properties of Amorphous Pharmaceuticals and Their Impact on Stability II: Stability of a Vaccine. Pharm. Res. 2007, 24 (4), 715-727. https://doi.org/10.1007/s11095-006-9191-2.

(47) Abdul-Fattah, A. M.; Kalonia, D. S.; Pikal, M. J. The Challenge of Drying Method Selection for Protein Pharmaceuticals: Product Quality Implications. J. Pharm. Sci. 2007, 96 (8), 1886-1916.

(48) Ji, W.; Sun, Y.; Yang, F.; van den Beucken, J. J. J. P.; Fan, M.; Chen, Z.; Jansen, J. A. Bioactive Electrospun Scaffolds Delivering Growth Factors and Genes for Tissue Engineering Applications. Pharm. Res. 2011, 28 (6), 1259-1272. https://doi.org/10.1007/s11095-010-0320-6.

(49) Klein, S.; Kuhn, J.; Avrahami, R.; Tarre, S.; Beliavski, M.; Green, M.; Zussman, E. Encapsulation of Bacterial Cells in Electrospun Microtubes. Biomacromolecules 2009, 10 (7), 1751-1756. https://doi.org/10.1021/bm900168v. 
(50) Bioinicia. Bioinicia Is Awarded GMP Certification for Its Industrial Manufacturing Plant for Electrospun Nanofibers . https://bioinicia.com/bioinicia-gmp-certificationfor-electrospun-nanofibers/ (accessed Mar 5, 2019).

(51) Lynch, D. H.; Roberts, L. K.; Daynes, R. A. Skin Immunology: The Achilles Heel to Transdermal Drug Delivery. J. Control. Release 1987, 6 (1), 39-50. https://doi.org/10.1016/0168-3659(87)90062-9.

(52) Sahdev, P.; Ochyl, L. J.; Moon, J. J. Biomaterials for Nanoparticle Vaccine Delivery Systems. Pharm. Res. 2014, 31 (10), 2563-2582. https://doi.org/10.1007/s11095-0141419-y.

(53) Foged, C.; Brodin, B.; Frokjaer, S.; Sundblad, A. Particle Size and Surface Charge Affect Particle Uptake by Human Dendritic Cells in an in Vitro Model. Int. J. Pharm. 2005, 298 (2), 315-322. https://doi.org/10.1016/j.ijpharm.2005.03.035.

(54) De Koker, S.; Lambrecht, B. N.; Willart, M. A.; Van Kooyk, Y.; Grooten, J.; Vervaet, C.; Remon, J. P.; De Geest, B. G. Designing Polymeric Particles for Antigen Delivery. Chem. Soc. Rev. 2011, 40 (1), 320-339. https://doi.org/10.1039/B914943K.

(55) O'Hagan, D. T.; Jeffery, H.; Davis, S. S. Long-Term Antibody Responses in Mice Following Subcutaneous Immunization with Ovalbumin Entrapped in Biodegradable Microparticles. Vaccine 1993, 11 (9), 965-969. https://doi.org/10.1016/0264410X(93)90387-D.

(56) De Groot, A. S.; Scott, D. W. Immunogenicity of Protein Therapeutics. Trends Immunol. 2007, 28 (11), 482-490. https://doi.org/10.1016/j.it.2007.07.011.

(57) Haj-Ahmad, R.; Khan, H.; Arshad, M. S.; Rasekh, M.; Hussain, A.; Walsh, S.; Li, X.; Chang, M.-W.; Ahmad, Z. Microneedle Coating Techniques for Transdermal Drug Delivery. Pharmaceutics 2015, 7 (4), 486-502. https://doi.org/10.3390/pharmaceutics7040486.

(58) Gill, H. S.; Prausnitz, M. R. Coating Formulations for Microneedles. Pharm. Res. 2007, 24 (7), 1369-1380. https://doi.org/10.1007/s11095-007-9286-4.

(59) Uddin, M. J.; Scoutaris, N.; Klepetsanis, P.; Chowdhry, B.; Prausnitz, M. R.; Douroumis, D. Inkjet Printing of Transdermal Microneedles for the Delivery of Anticancer Agents. Int. J. Pharm. 2015, 494 (2), 593-602. https://doi.org/10.1016/j.jpharm.2015.01.038.

(60) Guo, Q.; Mather, J. P.; Yang, P.; Boden, M.; Mather, P. T. Fabrication of Polymeric Coatings with Controlled Microtopographies Using an Electrospraying Technique. PLoS One 2015, 10 (6), e0129960. https://doi.org/10.1371/journal.pone.0129960. 
Figures

a)
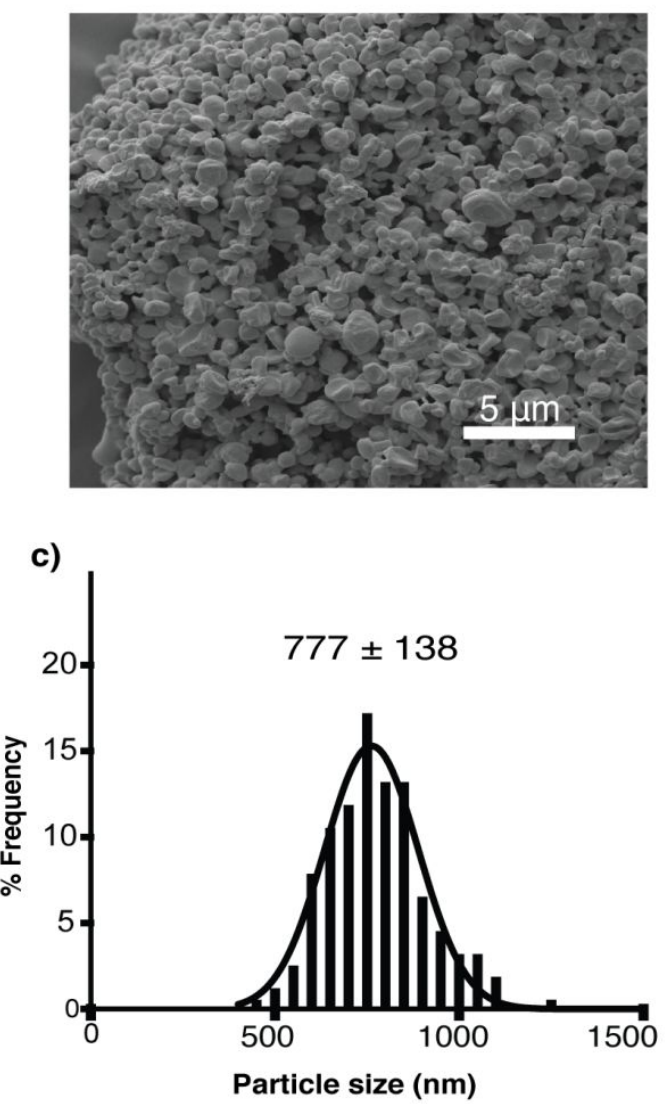

b)
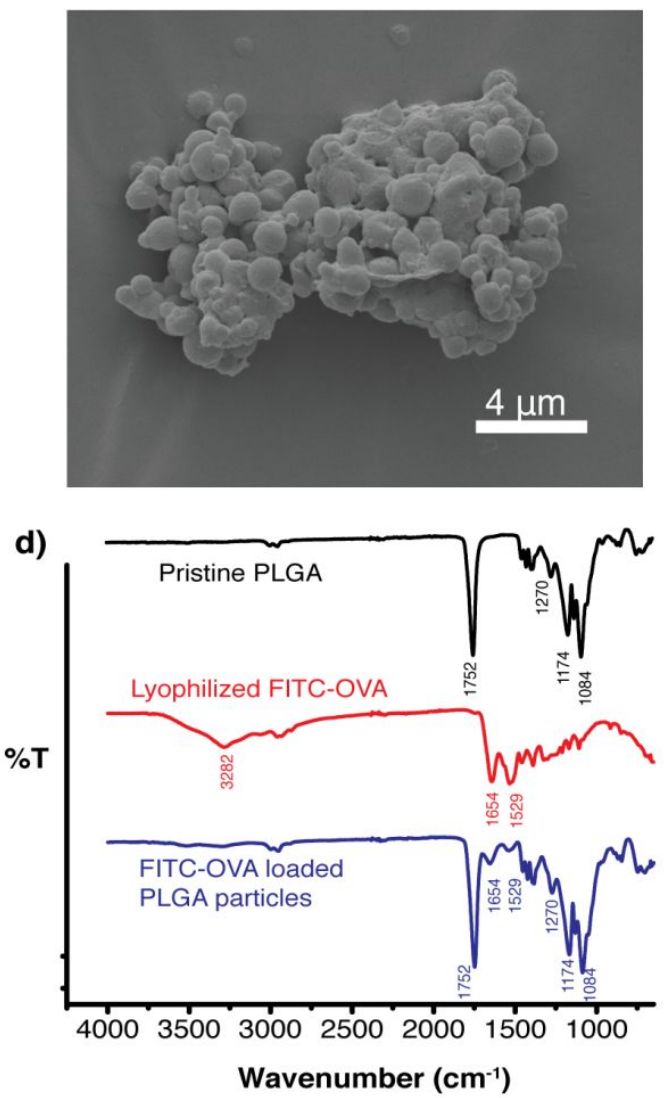

Figure 1 Morphological and chemical characterization of electrosprayed FITC-OVA loaded PLGA particles. SEM images of the samples at a) $10000 \times$ and b) $20000 \times$ magnification, with c) the particle size distribution. d) FTIR spectra of pristine PLGA, lyophilized FITC-OVA, and FITC-OVA loaded PLGA particles. 
a)

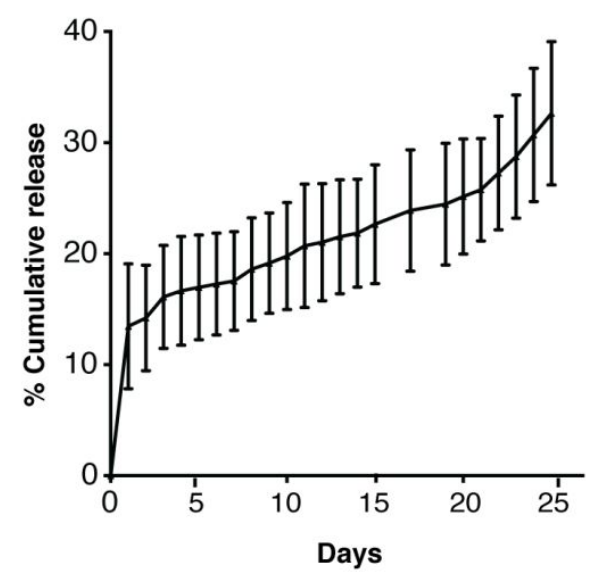

b)

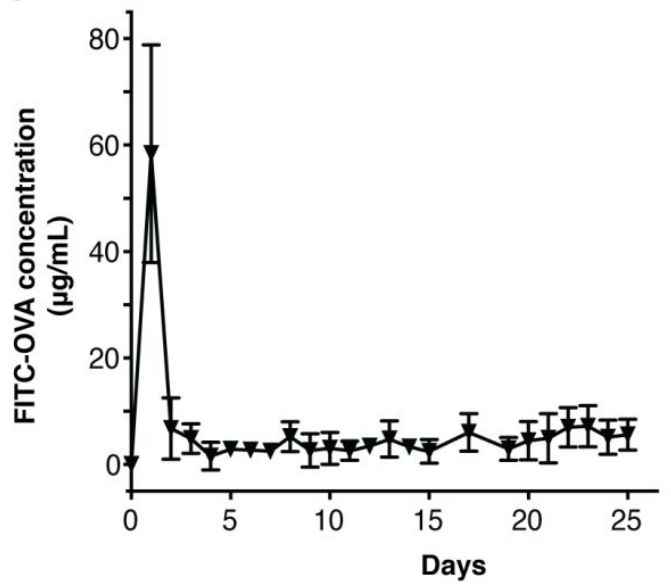

Figure 2 The release profiles of the FITC-OVA/PLGA particles showing a) cumulative release and b) concentration vs time profiles. Data are shown as mean \pm S.D. $(n=3)$. 

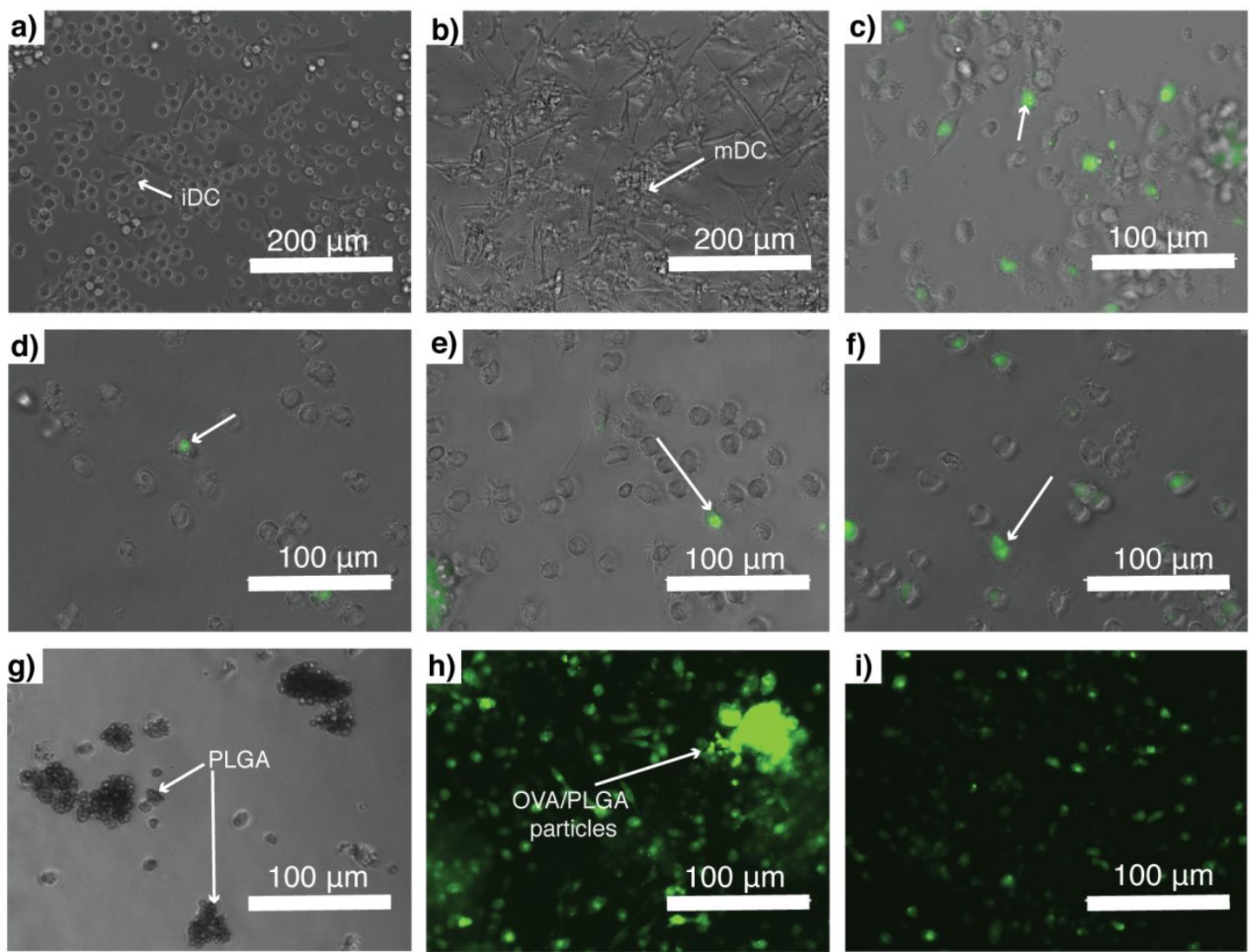

Figure 3 MoDC morphology after $24 \mathrm{~h}$ incubation with FITC-OVA formulations, showing GFP-overlay fluorescence microscopic analyses of a) untreated cells , and cells treated with b) $\underline{\mathbf{L P S}}(0.1 \mu \mathrm{g} / \mathrm{mL}$; positive control), c) $\underline{\mathbf{P 1}}$ (9.0 mg of the labeled OVA particles/well, $5.0 \mathrm{mg} / \mathrm{mL}$ FITC-OVA), d) $\underline{\mathbf{P 2}}(0.09$ $\mathrm{mg}$ of the labeled particles; 100-fold dilution of P1), e) $\underline{\mathbf{S 1}}(5.0 \mathrm{mg} / \mathrm{mL}$ soluble FITC-OVA), f) $\underline{\mathbf{S 2}}(0.05$ $\mathrm{mg} / \mathrm{mL}$ soluble FITC-OVA) and g) PLGA ( $8 \mathrm{mg} /$ well PLGA). GFP-filtered fluorescence images are also given for h) $\underline{\mathbf{P 1}}$ and i) $\underline{\mathbf{S 1}}$. MoDC showed uptake of FITC-OVA from all formulations (P1, P2, S1 and S2) after $24 \mathrm{~h}$. Particle aggregates were observed, on the surfaces of which MoDC tended to adhere, whereas the solution-treated cells spread over the wells. Arrows in c), d), e), f) indicate intracellular FITC. One representative experiment out of three is presented. Abbreviations: iDC-immature dendritic cells and $m D C-$ mature dendritic cells. 


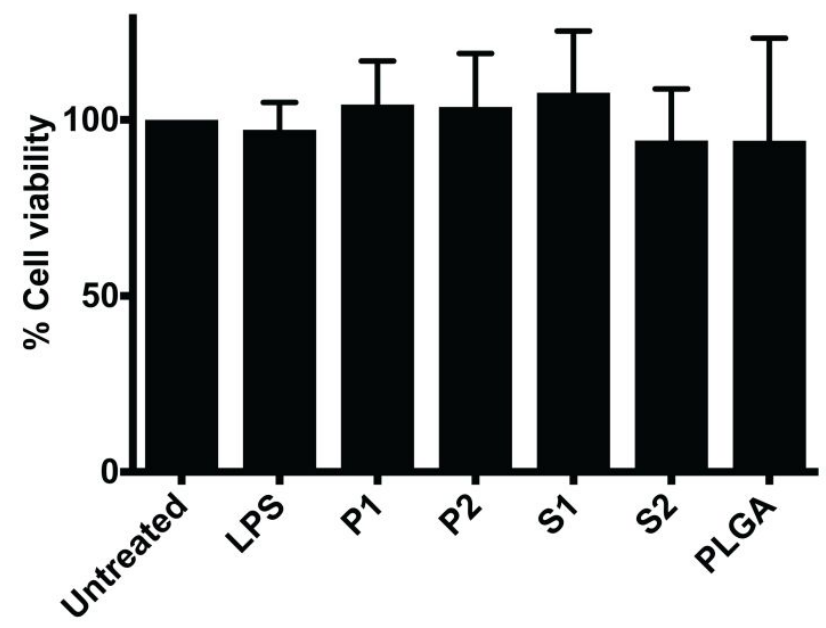

Figure $4 \mathrm{MoDC}$ viability after a $24 \mathrm{~h}$ incubation with FITC-OVA/PLGA particles. LPS $(0.1 \mu \mathrm{g} / \mathrm{mL}$, positive control); $\underline{\mathbf{P 1}}$ (9.0 mg of the labeled OVA particles/well; $5.0 \mathrm{mg} / \mathrm{mL}$ FITC-OVA); $\underline{\mathbf{P 2}}(0.09 \mathrm{mg}$ of the labeled particles, 100-fold dilution of P1); $\underline{\mathbf{S 1}}(5.0 \mathrm{mg} / \mathrm{mL}$ soluble FITC-OVA); $\underline{\mathbf{S 2}}(0.05 \mathrm{mg} / \mathrm{mL}$ soluble FITC-OVA) and PLGA (8 mg of PLGA/well). None of the formulations had any no effect on cell viability (repeated measures one-way ANOVA, $p>0.05$ ). The results are presented as mean $\pm \mathrm{SD}$ $(n=3)$. 

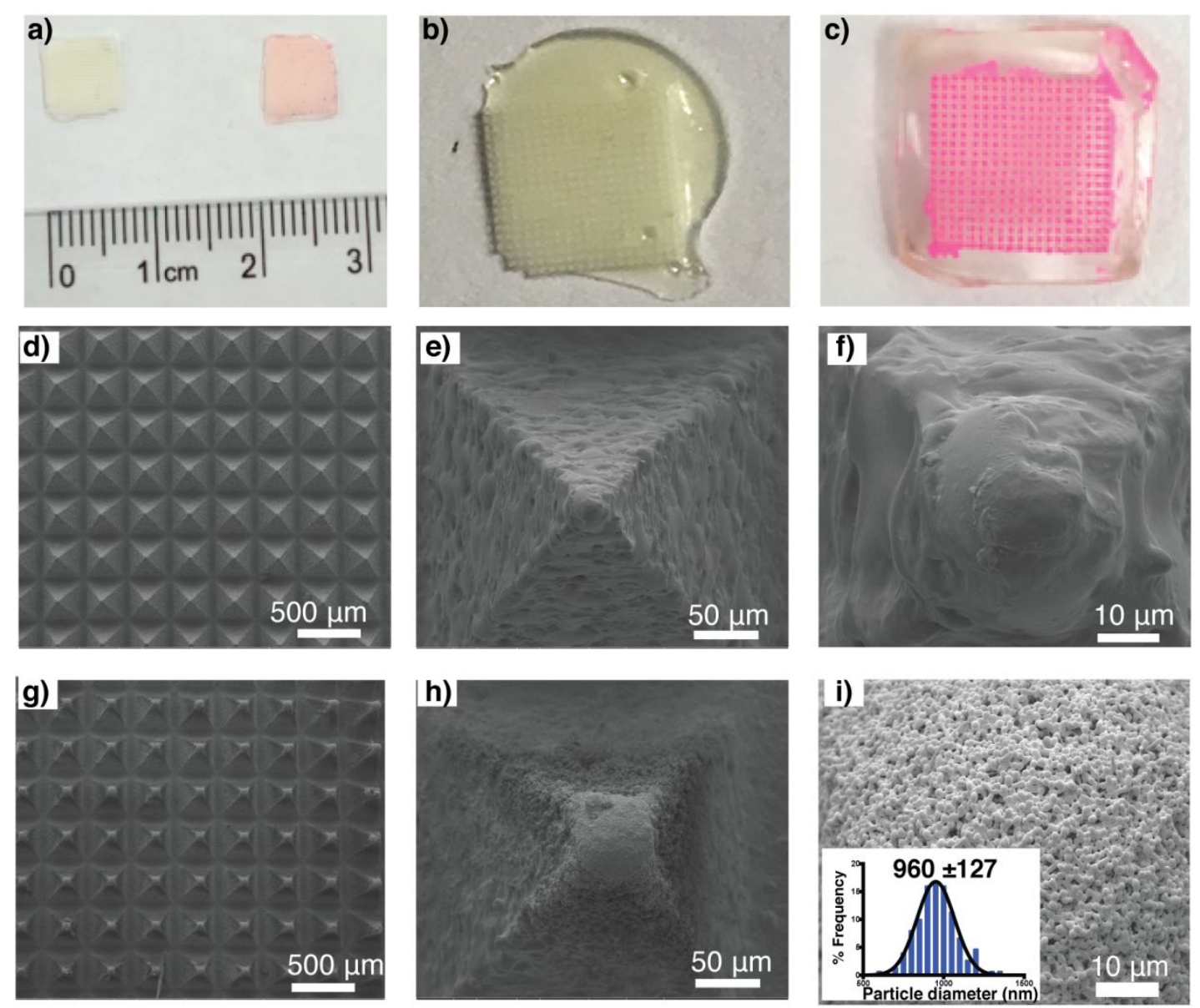

Figure 5 Photographs of a) uncoated (left) and coated (right) hydrogel-forming MN arrays with scale, and the close-up images of b) uncoated and c) coated MN arrays. SEM images showing the morphology of an uncoated MN array at d) $100 \times$, e) $1000 \times$, and f) $5000 \times$ magnification. Coated MN arrays at g) $100 \times$, h) $1000 \times$, and i) $5000 \times$ magnification, with the particle size distribution. 
a)

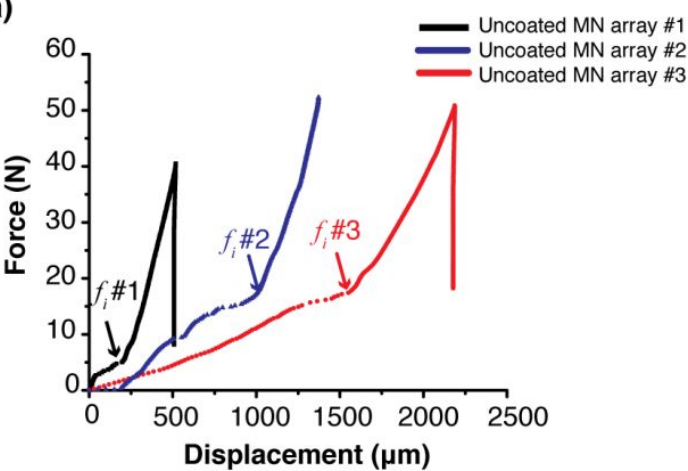

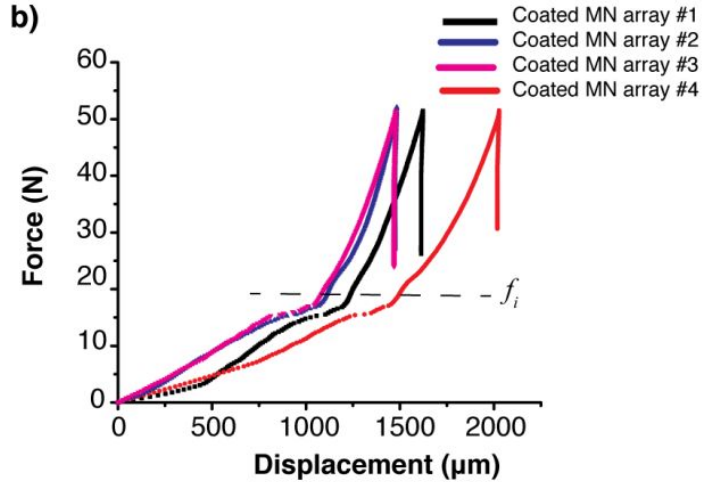

Figure 6 Force-displacement curves of $\mathrm{MN}$ a) before and b) after coating. The labeled discontinuity in the curve is identified as the force of insertion $\left(f_{i}\right)$. 


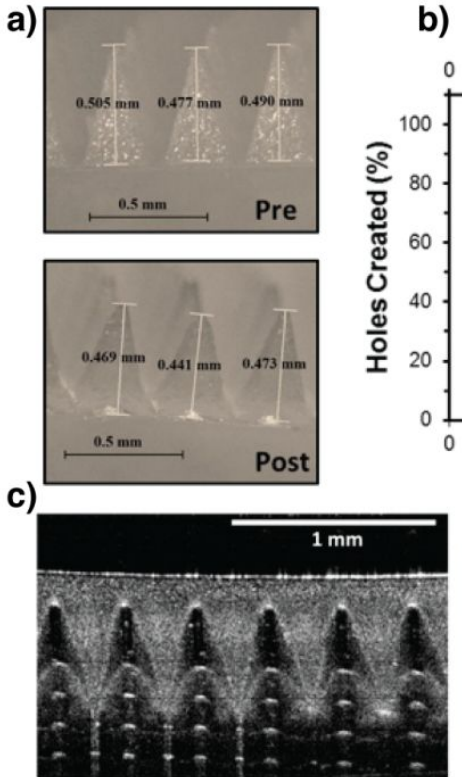

e)

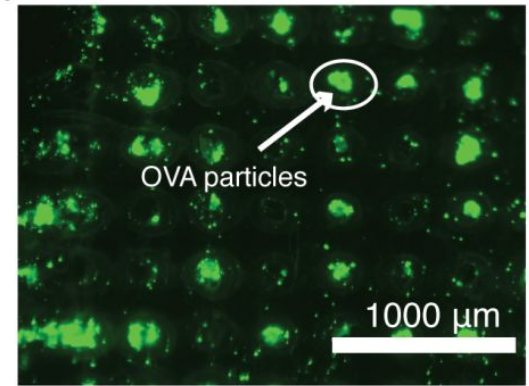

d) b) Parafilm Layer

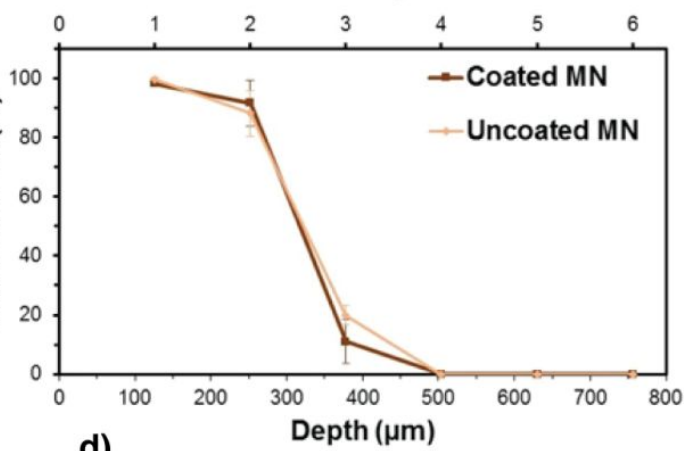
ii

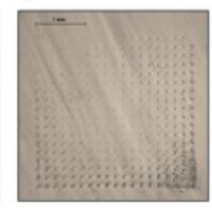

iii

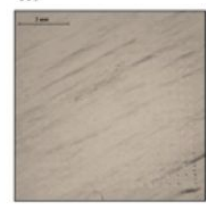

f)

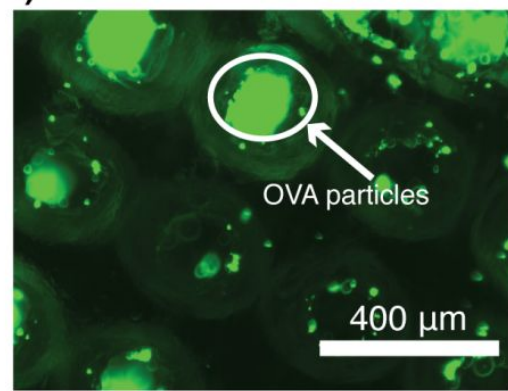

Figure 7 a) Representative light microscope images of coated MNs indicating needle heights pre- and post- insertion into Parafilm $\mathrm{M}^{\circledR}$. b) Line graph showing the relationship between insertion of MN arrays (coated and uncoated) and the number of holes created, depth of insertion, and layer of Parafilm $\mathrm{M}^{\circledR}$ reached following compression at $32 \mathrm{~N}$ for $30 \mathrm{~s}$, $(\mathrm{n}=3$, mean \pm S.D.). c) A representative optical coherence tomography image of coated $\mathrm{MN}$ insertion into Parafilm $\mathrm{M}^{\circledR}$. d) Light microscope images of Parafilm $\mathrm{M}^{\circledR}$ layers i) 1, ii) 2, and iii) 3 following the insertion of coated MN arrays. GFP-filtered fluorescent microscope images at e) $4 \times$ magnification and f) 10× magnification showing deposited particles on the second layer after MN insertion. 


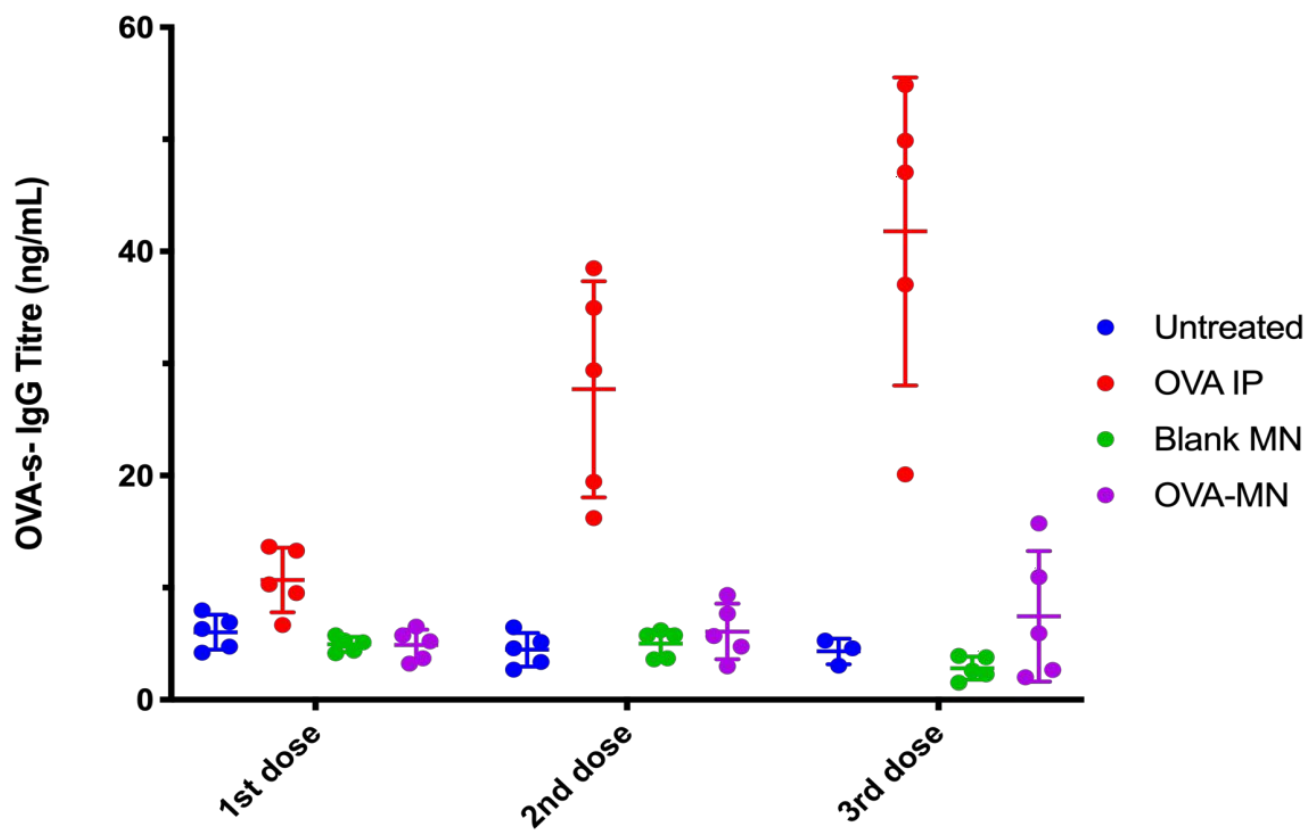

Figure 8 The results of in vivo experiments to evaluate the immunogenicity of the OVA-loaded coated MNs. Data are shown as mean \pm S.D. $(n=5)$. 


\section{Graphical abstract}

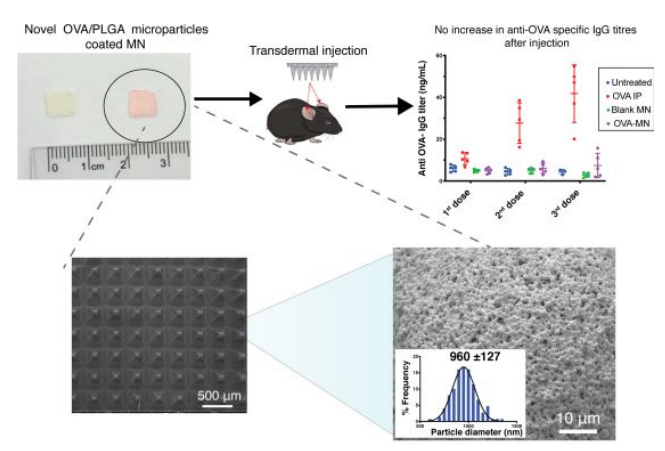

For Table of Contents Only 